\title{
Family care-giving and living arrangements of functionally impaired elders in rural China
}

\author{
ROB J. GRUIJTERS*
}

\begin{abstract}
China has seen a rapid decline of the traditional multi-generational household and an increase in rural-to-urban migration, raising concerns about a possible breakdown of the informal support system. Against this background, the paper looks at family care-giving (or the absence thereof) to parents in three different living arrangements: with any child or child-in-law (co-resident); independent with at least one child living in the same community (networked); and without any children in either the household or the community (isolated). It also compares the caregiving arrangements of single elders to those living with a spouse. The sample, which is derived from the comprehensive China Health and Retirement Longitudinal Study (CHARLS), contains data on 887 functionally impaired individuals aged 6o and above. The findings suggest that married parents are mostly cared for by their spouse, even if they co-reside with adult children. Proximity to children is particularly important for single elders, who are more likely to lack a caregiver when living independently. There appears to be a hierarchy in family care responsibilities, where children step in as care-givers only when the spouse is no longer able to fulfil this role. While these findings imply a significant deviation from traditional practices and norms of 'filial piety', they can be interpreted as a rational adaptation to the changed economic circumstances in rural China.
\end{abstract}

KEY WORDS - family care, living arrangements, inter-generational relations, older people, rural China, China Health and Retirement Longitudinal Study (CHARLS).

\section{Introduction}

In rural China, children are typically seen as the main source of security in later life. The Confucian norm of 'filial piety' obliges adult children to provide their parents with financial and material support as well as physical care and assistance. The multi-generational household, in which older parents co-reside with their adult children, is often seen as the embodiment

* Berlin Graduate School of Social Sciences, Humboldt-Universität zu Berlin, Germany. 


\section{Rob J. Gruijters}

of this informal support system (Silverstein, Cong and Li 20o6; Whyte 2004). In recent decades, however, living arrangements of rural Chinese elders have become more fluid and diversified. Most notably, there has been a steep decline in co-residence rates. At the same time, a number of non-traditional living arrangements have risen into prominence, including the 'empty nest' (older people living alone or with a spouse only) and the 'skipped generation household' (older people living with grandchildren whilst the middle generation lives and works elsewhere).

The causes and consequences of changes in living arrangements are the topic of a lively debate both in the Chinese public discourse and in academic literature (see e.g. Benjamin, Brandt and Rozelle 2000; Biao 2007; Giles and Mu 2007; Giles, Wang and Zhao 201 1; Silverstein, Cong and Li 2006; Zhang 2004). The decline in co-residence rates is normally attributed to China's transformation from a planned economy to a market-based system. Although successful in terms of stimulating economic growth and reducing absolute poverty rates, China's economic reforms were accompanied by an increase in socio-economic inequality, particularly between urban and rural areas. This led to a massive outflow of workers from the countryside to the cities: the National Bureau of Statistics (2013) estimated the total 'floating population' in 2012 at 236 million.

Since most migrants belong to younger age cohorts, ${ }^{1}$ large-scale out-migration has raised concerns about the wellbeing of older generations. They are often portrayed as victims of socio-economic modernisation and cultural change, left behind by their children who have moved to the cities in search of a better life. The decline of the multi-generational household is seen as a worrying trend that reflects a weakening of traditional norms of filial piety and inter-generational support (Croll 20o6; Zhang, $\mathrm{Gu}$ and Luo 2014).

Others have argued that changes in living arrangements do not necessarily reflect a weakening of the inter-generational support system. Both in China and other East Asian countries, it has been observed that the decline in co-residence rates has been partially offset by a corresponding increase in older people living independently in close proximity to their children (Knodel and Ofstedal 2002; Lei et al. 2011; Whyte 2004). This arrangement has been alternatively described as a 'networked' family or 'intimacy at a distance' (Thang 2010: 206). From this perspective, separate residences can be seen as a wealth effect reflecting both generations' preferences for privacy and independence (Giles, Wang and Zhao 2011). Living apart does not preclude the maintenance of close inter-generational ties nor the receiving of intensive support from adult children (Croll 2006).

Thus far, the academic discussion on social change and informal family support in rural China has mainly focused on the financial dimension, in 
particular the remittances provided by migrant children. This paper looks at another, equally important aspect of family support: the provision of care to older people with functional disabilities. Contrary to financial or even emotional support, care-giving requires frequent face-to-face contact (Silverstein and Litwak 1993), which makes it particularly vulnerable to large-scale outmigration. It is thus surprising that there is little empirical research relating family care-giving to the recent phenomena of rural-to-urban migration and decreasing co-residence rates.

This paper seeks to fill this void by providing detailed statistics on the caregiving arrangements of physically impaired older adults, in line with the overarching research question 'How does care provision vary by living arrangement?' In order to assess the importance of the proximity of children, it compares older parents in three different living arrangements: with any child or child-in-law (co-resident); independent with at least one child living in the same community (networked); and without any children in either the household or the community (isolated). Multivariate logistic regression models were used to assess how they differed in their respective likelihood of not having any care-giver, receiving care from a child and receiving care from a spouse. Further analyses were conducted by marital status and age cohort.

The findings contribute to related literature by (a) providing a more extensive typology of living arrangements, (b) considering various types of family care-givers in addition to adult children and (c) using a recent and nationally representative sample. Data were derived from the 2011-12 China Health and Retirement Longitudinal Study (CHARLS), which is the most comprehensive source of information on older adults in China. In line with the substantive interest of the paper, the sample was limited to individuals over 6o who lived in rural areas ${ }^{2}$ and had an explicit need for care. The issue of informal family care is particularly crucial in rural China because of the virtual absence of formal long-term care facilities, most of which are located in urban areas (Chow 2011; Ikels 2008). At the same time, demographic trends such as reduced fertility, out-migration and increased longevity put increasing pressure on the inter-generational support system. ${ }^{3}$ The findings of this paper provide a first indication of how family care networks are responding to these on-going challenges.

\section{Background and hypotheses}

\section{Family care-giving in East and West}

The selection of family care-givers to frail older people is a complex process in which the availability of potential care-givers, the needs of the recipient, 
as well as cultural norms and expectations all play an important role. Cantor's influential hierarchical-compensatory model of care-giving assumes that various categories of care-givers follow a descending order of preference. In Western societies, the primary care-giver of choice is normally the spouse, followed by children (particularly daughters) and more distant relatives (Cantor 1979). Formal options such as residential care facilities may be called upon when care needs exceed the capacity of the informal support network.

In rural China, on the other hand, formal long-term care facilities tend to be either absent or unaffordable. Like other Asian countries, China has a strong tradition of children caring for parents. According to Zhan and Montgomery,

Traditional patterns of parent care have been widely attributed to the deeply rooted cultural belief of xiao, or filial piety, which has been long believed to be the essential element holding together the Chinese familial system of care, determining who is likely to be a care provider, and deciding the types and amount of care that are provided. (2003: 210)

In the typical case, older Chinese would live with the family of their oldest son and receive physical care from their daughter-in-law (Cong and Silverstein 2011; Holroyd and Mackenzie 1995; Zhan and Montgomery 2003; Zimmer and Kwong 2003). It is unclear to what extent this traditional pattern still holds following the decline of the multi-generational household. Several authors have observed that hierarchical norms of filial obligation have weakened, as children increasingly focus on their own nuclear family (Du 2013; Miller 2007; Zhang 2004). The following sections outline the most common family constellations in contemporary rural China and hypothesise about their relation to care-giving arrangements.

\section{The decline of the multi-generational household}

Living arrangements have changed particularly rapidly in rural China: the percentage of older people that live with an adult child has declined from almost 70 per cent in 1991 to just over 40 per cent in 2006 (Cai et al. 2012: 48). It is often assumed that sharing a household with children is advantageous for elders, since various types of support and transfers tend to occur naturally and unacknowledged (Arber 2013; Thang 2010). Indeed, various studies identified important benefits from co-residence, including better mental health (Silverstein, Cong and Li 20o6), a lower risk of poverty (Yang 2010) and more help from children (Song, Li and Feldman 2012). There is a widespread concern in China and other Asian countries that declining co-residence rates reflect the weakening of inter-generational ties and threaten the informal support network of older people (see e.g. 
Benjamin, Brandt and Rozelle 200o; Biddlecom, Chayovan and Ofstedal 2002; Guo, Chi and Silverstein 2009; Silverstein, Cong and Li 2006). Care-giving, in particular, requires frequent physical contact and is thus most easily provided by relatives that live with or nearby the recipient (Litwak and Kulis 1987; Silverstein and Litwak 1993). For this reason, Zhang and Yeung believe that increased rural-urban migration, changing family structures and the rising number of nuclear households raise questions about 'the sustainability of the family institution in the provision of care' (2012: 615). Thus far, no study has compared care-giving constellations of co-resident and non-co-resident Chinese elders, although Peng, $\mathrm{Wu}$ and Ling (2014) found that living alone increased the risk of having unmet care needs. Also, a study from rural Thailand has shown that parents living independently are much less likely to receive care from a child (Knodel and Chayovan 2012). This leads to the hypothesis that older adults who do not co-reside with children are (a) less likely to receive support from children and (b) more likely not to have a caregiver (Hypothesis 1).

\section{The networked family perspective}

Not all observers see the decline of the multi-generational household in negative terms. Recent qualitative studies suggest that even though the multi-generational household is still a traditional ideal in rural China, 'the aged do not necessarily prefer or benefit from co-residence with their children' (Miller 2007: 32). Stress and conflicts caused by co-residence for both older and younger generations are frequently recurring themes. Many older Chinese have adapted their preferences and 'no longer see co-residence with a married son as the ideal manifestation of filial piety' (Thøgersen and Anru 2008: 22) or are afraid of becoming a burden to their families. Proponents of this view, which is more dominant in recent works, have pointed out that most non-co-resident parents live close to one or more of their children (sometimes in adjacent residences) and receive extensive support from them (Hermalin 2002; Lei et al. 2011; Cai et al. 2012). In a meta-study of ethnological findings from across Asia, Croll concludes that 'the resource flows hitherto associated with coresidence are not constrained by the physical boundaries of separate households and that living near, as opposed to with, children does not necessarily mean that there are fewer resource flows between the generations' (2006: 485 ). The concept of the 'networked family' is often used to describe 'the relations, exchanges and connections between separate but close-kin related nuclear households' (Croll 20o6: 485). Networked parents enjoy the benefits of proximity whilst avoiding the downsides of co-residence, 
which include a lack of privacy and an increased potential for inter-generational conflict (Giles, Wang and Zhao 2011; Zhang 2004). In China, it has been observed that frail older people increasingly value and receive assistance from non-co-resident married daughters, whose traditional role is to look after their parents-in-law (Liu 2014; $\mathrm{Xu} 2001$; Zhan and Montgomery 2003). From this perspective, there is thus no reason to expect substantial differences in care-giving arrangements between the networked and the co-resident categories (Hypothesis 2).

\section{Care-giving by spouses and other relatives}

It appears that isolated older adults, who are neither co-resident nor have children living nearby, are worst off in terms of care-giving. Children's propensity to provide care is normally found to decline gradually with geographical distance or travel time (e.g. Litwak and Kulis 1987), which suggests that the isolated category is least likely to receive support from children, and most likely to lack a care-giver (Hypothesis 3 ).

That being said, proximity to children is not the only factor that determines whether care needs are provided for. The presence of alternative care-givers such as a spouse or (adult) grandchildren may reduce the need to rely on children for support. The role of the spouse, in particular, has been largely neglected in studies on informal family care in China, presumably because of the perceived primacy of adult children as care-givers. It is likely, however, that the large-scale out-migration of children and corresponding decline in co-residence rates have increased the importance of spouses as care-givers, particularly for men. In the absence of empirical studies on spousal care-giving in China, it can be insightful to look at studies from neighbouring countries that share some of rural China's socio-economic characteristics. For example, in rural Thailand spouses were found to be the most common care-giver for married elders, particularly if they did not live with or close to children (Knodel and Chayovan 2012). In rural Vietnam, on the other hand, spouses were found to play a relatively marginal role, but receiving care from grandchildren was common (Hoi, Thang and Lindholm 2011). I therefore hypothesise that the presence of a spouse or a grandchild can mediate the negative impact of not living with children, particularly for isolated elders (Hypothesis 4 ).

Finally, it has been observed that the division of labour between family care-givers tends to shift over the lifecourse. In Western countries, married parents most often receive care from their spouse. Children and other relatives generally take over primary care-giving responsibilities after widowhood or when the spouse experiences health problems, typically at a later stage in life (Chappell 1991; Penning 1990). It is uncertain 
whether a similar pattern holds in China, where taking care of elders is generally considered to be the responsibility of their children, and filial norms are more strongly developed than in the West (Cong and Silverstein 2011; Holroyd and Mackenzie 1995; Whyte 2003). According to $\mathrm{Xu}$, however, 'spousal support can often postpone or avoid the period of complete dependency on children' (2001: 310), and it was observed that some parents transition into co-residence after widowhood or when their health deteriorates (Zimmer 2005; Zimmer and Korinek 2010; Zimmer and Kwong 2003). We would therefore expect the role of different care-givers to vary by age, with 'younger old' parents more likely to receive care from a spouse and the 'oldest old' more likely to receive care from a child (Hypothesis 5).

\section{Data and methodology}

\section{Sample}

All analyses are based on data derived from the National Baseline of the CHARLS, which was conducted in 2011-12 (see Zhao et al. 2013). CHARLS is part of a family of surveys modelled on the American Health and Retirement Survey (HRS), including amongst others the Survey of Health, Ageing and Retirement in Europe (SHARE) and the Japanese Study on Ageing and Retirement (JSTAR). The Gateway to Global Aging Data created a harmonised version of CHARLS, which is comparable to the RAND HRS and other harmonised data-sets. Wherever possible, this study used the harmonised variables.

CHARLS covers 28 out of 30 provinces in China and is nationally representative of the non-institutionalised population over the age of 45.4 It has a total sample size of 17,708 individuals in 10,257 households (in cases where the main family respondent was married, the spouse was included in the sample as well). Each survey contains highly detailed information on topics such as demographics, family support and transfers, health status and functioning, employment, pensions, income and assets. Data quality was ensured by employing a Computer Assisted Personal Interviewing system as well as extensive quality checks and follow-ups. The rural response rate amounted to 94.15 per cent (Zhao et al. 2013 ).

For the purposes of this paper, I only looked at respondents that lived in rural areas and had reached the age of 6o, which is generally seen as the start of old age in China (being, for example, the eligible age to receive the New Rural Pension) (Lei et al. 2011). Moreover, I restricted the sample to respondents with at least one living child and at least one serious functional impairment (see below). After deleting 157 cases due to 
missing values on some key variables, the sample was reduced to 887 parents. In 79 households both husband and wife were over 60 and had a need for care. In this case, each spouse is both a potential care recipient and a potential care-giver (standard errors are clustered by household to correct within-household correlation in these cases).

\section{Dependent variables}

I follow Uhlenberg in defining care-giving as 'assistance provided to persons who cannot, for whatever reason, perform the basic activities or instrumental activities of daily living for themselves' (1996: 762). Activities of Daily Living (ADLs) and Instrumental Activities of Daily Living (IADLs) are standard measures of functional ability that have been incorporated in most health-related household surveys (Vlachantoni et al. 2013; Wolff and Kasper 2006). In CHARLS, difficulties with each ADL (dressing, bathing, eating, getting out of bed, using the toilet, controlling urination and defecation) and IADL (doing chores, preparing hot meals, shopping, managing money, making phone calls, taking medications) are measured on a fourpoint scale: $1=$ I don't have any difficulty, $2=\mathrm{I}$ have difficulty but can still do it, 3 = I have difficulty and need help and $4=$ I cannot do it.

Respondents are considered functionally impaired and included in the sub-sample if they responded (3) or (4) to at least one ADL or IADL, which is true for 23 per cent of the total sample of rural people above the age of 60 (note that the analytical sample thus includes only respondents who explicitly state their need for care and excludes those who merely express difficulty). These respondents were asked the follow-up question 'Who most often helps you with [list of ADLs and IADLs]?' Possible responses included various categories of family members, paid helpers or volunteers, as well as 'no one helped'. Although they could theoretically indicate up to three individuals, most mentioned only one (7o per cent) or two (17 per cent) primary care-givers. For the regression analyses these answers are converted to four binary outcome variables representing (a) not having any care-giver, (b) receiving care from any child or child-inlaw, (c) receiving care from a spouse and (d) receiving care from a grandchild.

\section{Independent variables}

The primary variable of interest in this study is the living arrangement of the parent in relation to his or her children. Many observers believe that close proximity to children can be a functional equivalent to co-residence, whereas others see any kind of non-co-residence as a sign of weakened 
inter-generational ties. In order to test these hypotheses, living arrangement is divided into three categories:

- Co-resident (sharing a household with any child and/or child-in-law).

- Networked (not co-resident, but with at least one child living in the same village).

- Isolated (not co-resident, all children living outside the village).

\section{Control variables}

Respondent gender. A number studies have shown than mothers are more likely to receive informal family care (e.g. Yarger and Brauner-Otto 2014; Zimmer and Kwong 2003). On the other hand, age differentials in marriage and the gendered nature of care-giving suggest that men are more likely to receive care from their spouse (Haberkern, Schmid and Szydlik 2015; Zhan and Montgomery 2003).

Intensity of care needs. Family care-giving decisions are generally responsive to parents' needs (e.g. Guo, Chi and Silverstein 2009; Silverstein and Litwak 1993; Song, Li and Feldman 2012). Whilst all parents in the analytical sample have an identified need for support, the intensity of this need may vary. I therefore control for age and for the number of (I)ADLs that the parent is not able to perform independently. ${ }^{5}$ Age is a particularly important control variable because it is strongly correlated with a number of other factors and lifecourse events that may affect care needs and caregiving, including health status, income-generating capacity and social status.

Potential care-givers. The probability that a parent receives care when needed is likely to increase with the number of potential care-givers. Respondents with a spouse may have a lower need to rely on children for support, but when both spouses have functional impairments this may reduce their capacity for mutual care. The marital status variable therefore has three categories: (a) married: healthy spouse, (b) married: spouse has care need and (c) single. The large majority of respondents belonging to the 'single' category are widowed. I also include the total number of children as well as a categorical variable indicating whether the children are all male, all female or both sexes. It is typically believed that parents who have both daughters and sons are better off in terms of care than those who have only sons or daughters (Xu 2001).

Socio-economic status (SES). The inter-generational reciprocity perspective assumes that parents who control assets or have an independent source of 
income are more likely to receive care transfers from their children, since they can reciprocate these by making financial transfers or bequests to the care-giver. On the other hand, high SES may relate to a more individualistic lifestyle, which reduces the probability of receiving family care (Yarger and Brauner-Otto 2014). I include two proxies for SES to control for these competing effects: education level (in three categories) and self-reported living standard (poor, average or high). ${ }^{6}$

\section{Analytical strategy}

In the first stage, logistic regression models were used to assess how living arrangements affect the likelihood of (a) not having any care-giver and (b) receiving care from a child or child-in-law, controlling for the variables described above. In order to assess how the presence of a spouse affects this relationship, these analyses were replicated for the married and single subsamples. Single elders are often considered a vulnerable group (Barrientos, Gorman and Heslop 2003), and their care-giving arrangements are thus of particular interest. Finally, I explore the role of age in more detail. Since CHARLS uses a clustered sampling design, sampling weights (which include a correction for non-response) are applied to all descriptive tables and figures. Note that the study is based on cross-sectional data and living arrangements are not exogenous to family care-giving; results should therefore not be interpreted as causal relationships.

\section{Results}

Table 1 provides descriptive statistics of all dependent and independent variables, separated by living arrangement. It shows that about $5^{2}$ per cent of sampled parents were co-resident, 34 per cent were networked and 14 per cent lived isolated from their children. The corresponding figures for non-impaired parents were 45, $3^{6}$ and 18 per cent, respectively, which suggests that co-residence was at least partially responsive to functional health, as Korinek, Zimmer and Gu (2011) have shown. The prevalence of networked extended families demonstrates that out-migration of children was not the only reason for non-co-residence: many functionally impaired elders maintained independent households rather than moving in with a nearby child.

Most sampled parents had three or more children,7 and just over a third did not have a spouse. They also tended to have little or no formal education and to rate their standard of living as (relatively) poor or average (see Table 1). Figure 1 plots living arrangement and the presence of a spouse 
T A B L E 1. Descriptive statistics for sample, by living arrangement

\begin{tabular}{|c|c|c|c|c|c|}
\hline Variables and categories & Co-resident & Networked & Isolated & Total & $\mathrm{N}$ \\
\hline & \multicolumn{5}{|c|}{ Percentages } \\
\hline \multicolumn{6}{|l|}{ Care-giver - none: } \\
\hline Has a care-giver & $89 \cdot 4^{1}$ & 83.01 & 81.01 & 86.28 & $75^{6}$ \\
\hline Has no care-giver & 10.59 & 16.99 & 18.99 & $13 \cdot 72$ & $13^{1}$ \\
\hline \multicolumn{6}{|l|}{ Care-giver - child: } \\
\hline No child (in-law) is care-giver & 40.85 & 80.90 & 92.94 & 60.39 & 601 \\
\hline Any child (in-law) is care-giver & 59.15 & 19.10 & 7.06 & 39.61 & 286 \\
\hline \multicolumn{6}{|l|}{ Care-giver - spouse: } \\
\hline No spousal care-giver & 67.10 & 35.08 & 31.98 & $5^{2.31}$ & 406 \\
\hline Spouse is care-giver & 32.90 & 64.92 & 68.02 & 47.69 & $4^{81}$ \\
\hline \multicolumn{6}{|l|}{ Care-giver - grandchild: } \\
\hline No grandchild is care-giver & 93.01 & 96.08 & 93.61 & 94.08 & $8_{3} 6$ \\
\hline Any grandchild is care-giver & 6.99 & 3.92 & 6.39 & $5 \cdot 92$ & $5^{1}$ \\
\hline \multicolumn{6}{|l|}{ Gender of respondent: } \\
\hline Male & 33.27 & 44.19 & $45 \cdot 74$ & $3^{8.3^{8}}$ & $3^{61}$ \\
\hline Female & 66.73 & 55.81 & 54.26 & 61.62 & $5^{26}$ \\
\hline \multicolumn{6}{|l|}{ Marital status: } \\
\hline Married: healthy spouse & 33.88 & 59.87 & 61.43 & $45 \cdot 77$ & 454 \\
\hline Married: spouse has care need & 17.15 & 20.03 & 25.10 & 19.09 & 185 \\
\hline Single/widowed & $4^{8.97}$ & 20.10 & 13.47 & 35.14 & 248 \\
\hline \multicolumn{6}{|l|}{ Functional limitations: } \\
\hline One care need & $3^{6.47}$ & $43 \cdot 44$ & 43.85 & 39.66 & 368 \\
\hline Two or three care needs & 29.85 & 29.82 & 34.20 & 30.40 & 267 \\
\hline Four or more care needs & 33.67 & 26.74 & 21.96 & 29.95 & $25^{2}$ \\
\hline \multicolumn{6}{|l|}{ Self-rated living standard: } \\
\hline Average & $\begin{array}{r}3.89 \\
49.89\end{array}$ & $\begin{array}{r}4.95 \\
42.52\end{array}$ & 50.60 & 47.60 & $\begin{array}{r}402 \\
402\end{array}$ \\
\hline (Relatively) poor & 46.22 & $5^{2.53}$ & $45 \cdot 3^{1}$ & $4^{8.14}$ & 445 \\
\hline \multicolumn{6}{|l|}{ Highest level of education: } \\
\hline No education & 66.98 & $5^{8.80}$ & 49.03 & 62.06 & 531 \\
\hline (Some) primary school & 27.65 & 34.87 & $44.5^{\circ}$ & 32.12 & 300 \\
\hline Middle school or higher & $5 \cdot 37$ & 6.33 & 6.47 & 5.82 & $5^{6}$ \\
\hline \multicolumn{6}{|l|}{ Number of children: } \\
\hline One & 10.99 & $3 \cdot 91$ & 11.18 & 8.73 & 75 \\
\hline Two & 16.77 & 10.00 & 20.19 & 15.02 & 124 \\
\hline Three or more & 72.23 & 86.10 & 68.63 & 76.25 & 688 \\
\hline \multicolumn{6}{|l|}{ Gender of children: } \\
\hline Both sons and daughters & $67 \cdot 30$ & 82.70 & $68.4^{8}$ & $72.4^{1}$ & 668 \\
\hline Sons only & 22.95 & 12.62 & 18.01 & 18.99 & 154 \\
\hline Daughters only & $9 \cdot 75$ & 4.68 & $13 \cdot 5^{1}$ & 8.60 & 65 \\
\hline Age (mean) & 72.54 & 72.03 & 68.97 & 71.92 & 887 \\
\hline Total & 55.03 & 32.25 & 12.72 & 100.00 & 887 \\
\hline
\end{tabular}

Note: Values are weighted percentages and unweighted $\mathrm{N}$. 

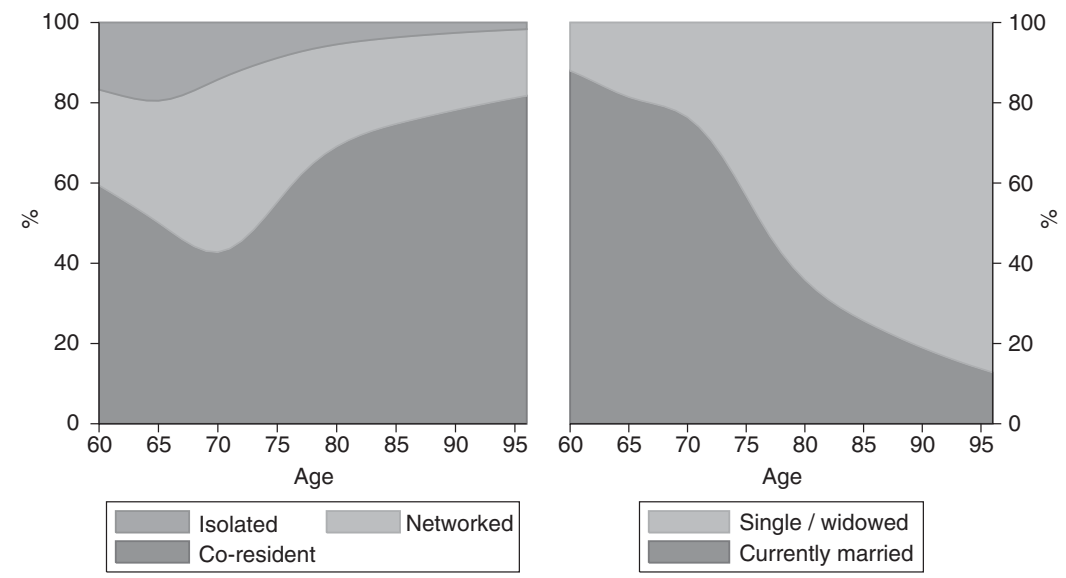

Figure 1. Living arrangement (left) and presence of spouse (right), by age of respondent. Notes: Stacked plots using restricted cubic spline smoothing of proportions. Based on the analytical sample (rural parents, $6 \mathrm{o}+$, at least one functional limitation: $\mathrm{N}=887$ ).

against age. Co-residence tends to increase from around age 70 , when a large number of parents have become widowed. As a result, co-resident parents are slightly older than average. Co-resident, networked and isolated parents differed in a number of other aspects as well. For example, the coresident group had more intensive care needs and isolated respondents were more likely to be male and to be married. All these variables will be controlled for in the regression analyses.

Table 1 also lists the primary care-givers of the sampled respondents. It shows that 14 per cent of the sample respondents did not have any caregiver, $4^{\mathrm{o}}$ per cent received care from a child (in-law) and 47 per cent from a spouse (note that respondents could indicate more than one primary care-giver). The high incidence of spousal care-giving, particularly for the networked and the isolated groups, highlights the need to pay more attention to this particular care arrangement. Grandchildren played a somewhat less important role: they were primary care-givers in about 6 per cent of all cases.

\section{The determinants of receiving informal family care}

Table 2 presents the results from two logistic regression models predicting the likelihood of not having any care-giver (Model 1) and receiving care from a child or child-in-law (Model 2). To facilitate their interpretation, I present the results both as odds ratios and as average predicted probabilities (calculated using the observed values of all other covariates). 
T А в L E 2. Logistic regression models, full sample

\begin{tabular}{|c|c|c|c|c|c|c|}
\hline & \multicolumn{3}{|c|}{ Model 1: No care-giver } & \multicolumn{3}{|c|}{$\begin{array}{l}\text { Model 2: Child (in-law) } \\
\text { care-giver }\end{array}$} \\
\hline & OR & SE & PP & OR & SE & PP \\
\hline \multicolumn{7}{|l|}{ Living arrangement: } \\
\hline Co-resident & Ref. & & 0.11 & Ref. & & $0.4^{6}$ \\
\hline Networked & $1.89^{*}$ & 0.49 & 0.18 & $0.22 * * *$ & 0.05 & 0.22 \\
\hline Isolated & $2.21 * *$ & 0.68 & 0.20 & $0.06^{* * *}$ & 0.03 & 0.09 \\
\hline \multicolumn{7}{|l|}{ Gender: } \\
\hline Male & Ref. & & 0.12 & Ref. & & 0.29 \\
\hline Female & 1.42 & $0.3^{2}$ & 0.16 & $1.53^{*}$ & 0.31 & 0.35 \\
\hline \multicolumn{7}{|l|}{ Intensity of need: } \\
\hline One care need & Ref. & & 0.23 & Ref. & & 0.31 \\
\hline Two or three care needs & $0.48^{* *}$ & 0.11 & 0.13 & 1.00 & 0.22 & $0.3^{1}$ \\
\hline Four or more care needs & $0.09^{* * *}$ & 0.04 & 0.03 & 1.44 & 0.33 & $0.3^{6}$ \\
\hline Age & $0.97^{*}$ & 0.02 & & $1.05 * *$ & 0.02 & \\
\hline \multicolumn{7}{|l|}{ Socio-economic status: } \\
\hline Living standard: (relatively) high & Ref. & & 0.06 & Ref. & & 0.31 \\
\hline Living standard: Average & 2.10 & 1.57 & 0.12 & 1.33 & 0.55 & 0.35 \\
\hline Living standard: (relatively) poor & $3.68 \dagger$ & 2.75 & 0.18 & 0.89 & 0.37 & 0.30 \\
\hline No education & Ref. & & 0.14 & Ref. & & 0.33 \\
\hline (Some) primary school & $1.5^{0 \dagger}$ & 0.36 & 0.18 & 0.86 & 0.20 & 0.31 \\
\hline Middle school or higher & 0.39 & 0.31 & 0.06 & 0.61 & 0.27 & 0.27 \\
\hline \multicolumn{7}{|l|}{ Potential care-givers: } \\
\hline Married: healthy spouse & Ref. & & 0.10 & Ref. & & 0.19 \\
\hline Married: spouse has care need & $2.09 *$ & 0.62 & 0.17 & $2.01 * *$ & 0.54 & 0.29 \\
\hline Single/widowed & $3 \cdot 4^{2 * * *}$ & $0.9^{8}$ & 0.24 & $8.67 * * *$ & 1.98 & $0.5^{6}$ \\
\hline One child & Ref. & & 0.24 & Ref. & & 0.28 \\
\hline Two children & $0.5^{8}$ & 0.28 & 0.16 & 1.35 & 0.59 & 0.32 \\
\hline Three or more children & $0.45^{\dagger}$ & 0.21 & 0.14 & 1.38 & 0.54 & 0.33 \\
\hline Both sons and daughters & Ref. & & 0.16 & Ref. & & 0.31 \\
\hline Sons only & 0.65 & 0.25 & 0.11 & 1.17 & 0.34 & 0.33 \\
\hline Daughters only & 0.84 & 0.34 & 0.14 & $3.83 * * *$ & $1.4^{8}$ & $0.5^{\circ}$ \\
\hline Observations & 887 & & & 887 & & \\
\hline Pseudo $R^{2}$ & 0.157 & & & 0.325 & & \\
\hline
\end{tabular}

Notes: OR: odds ratio. SE: robust standard error. PP: average predicted probability. Ref.: reference category.

Significance levels: $\dagger p<0.10, * p<0.05, * * p<0.01, * * * p<0.001$.

Predicted probabilities show that family care-giving was strongly related to living arrangements. As expected, the isolated group had the lowest probability of receiving care from a child. Contrary to the 'networked family' hypothesis, networked parents were much less likely to receive care from a child than co-resident parents ( 46 versus $22 \%$ ). Moreover, both networked and isolated parents were more likely to have unmet care needs ( 18 and $20 \%$, 
respectively). These findings suggest that the networked family is at best an imperfect alternative to co-residence. Descriptive evidence, however, suggests that most non-co-resident respondents live with their spouse and may thus be less dependent on adult children to meet their care needs. Indeed, the odds of having a child as primary care-giver were 8.7 times higher for single respondents than for respondents with a healthy spouse. Children were also more likely to be care-givers when both spouses had a physical impairment, which suggests that they step in when their parents are no longer capable of providing mutual care. The role of marital status and spousal caregiving will be explored further in the next section.

The control variables largely have the expected direction. For example, mothers and comparatively older parents were more likely to receive care from a child. Parents' SES appeared to be unrelated to child care-giving, although poor living standards increased the risk of not having a caregiver $(p<0.10)$. Perhaps surprisingly in the Chinese context, the number of children did not have a major effect on care-giving after controlling for living arrangement and other covariates. Zimmer and Kwong (2003) and Song, Li and Feldman (2012) came to a similar conclusion. It is thus the proximity to children that mattered for care-giving rather than the number of offspring. Child gender also played a role: parents with daughters only were more likely to receive care from children than those with only sons or children of both sexes.

\section{The role of marital status and alternative care-givers}

In order to understand better the role of marital status in defining caregiving arrangements, Tables 3 and 4 present analyses for parents living with and without a spouse. In line with Hypothesis 4 , I also consider the importance of alternative care-givers, notably the spouse for married respondents (Model 3) and grandchildren for single respondents (Model 6). The predicted probabilities from each model are plotted in Figure 2.

Figure 2 shows that spousal care-giving was predominant amongst married respondents. Even for respondents that were married and living with a child, the predicted probability of the spouse being a care-giver was 66 per cent, compared to 33 per cent for any child (in-law). Moreover, respondents that lived with a spouse had a constant, low risk of unmet care needs regardless of the proximity of children. As expected, men were more likely to receive care from their spouse.

Single respondents, most of whom were widowed, relied largely on children to fulfil their care needs. As a result, proximity to children was of more importance for this population segment. In particular, both isolated and networked respondents had much higher levels of unmet care needs 
T А В L E 3. Logistic regression models, currently married respondents

\begin{tabular}{|c|c|c|c|c|c|c|c|c|c|}
\hline & \multicolumn{3}{|c|}{ Model 1: No care-giver } & \multicolumn{3}{|c|}{$\begin{array}{l}\text { Model 2: Child } \\
\text { (in-law) care-giver }\end{array}$} & \multicolumn{3}{|c|}{$\begin{array}{l}\text { Model 3: Spouse } \\
\text { care-giver }\end{array}$} \\
\hline & OR & SE & $\mathrm{PP}$ & OR & SE & $\mathrm{PP}$ & OR & $\mathrm{SE}$ & $\mathrm{PP}$ \\
\hline Co-resident & Ref. & & 0.12 & Ref. & & 0.33 & Ref. & & 0.66 \\
\hline Networked & 1.07 & 0.34 & 0.13 & $0.20^{* * *}$ & 0.06 & 0.10 & $2.5^{8 * * *}$ & 0.64 & 0.81 \\
\hline Isolated & 1.21 & 0.43 & 0.14 & $0.10^{* * * *}$ & 0.05 & 0.05 & $2.35^{* *}$ & 0.67 & 0.80 \\
\hline Male & Ref. & & 0.08 & Ref. & & 0.15 & Ref. & & 0.84 \\
\hline Female & $2.39 * * *$ & 0.62 & 0.16 & $1.5^{8 \dagger}$ & $0.3^{8}$ & 0.21 & $0.34^{* * *}$ & 0.07 & 0.67 \\
\hline Observations & 639 & & & 639 & & & 639 & & \\
\hline Pseudo $R^{2}$ & 0.175 & & & 0.159 & & & $0.15^{1}$ & & \\
\hline
\end{tabular}

Notes: OR: odds ratio. SE: robust standard error. PP: average predicted probability. Ref.: reference category. Control variables (same as in Table 2) not shown: full table available upon request.

Possible significance levels: $\dagger p<0.10, * p<0.05, * * p<0.01, * * * p<0.001$.

T А В L E 4 . Logistic regression models, single respondents

\begin{tabular}{|c|c|c|c|c|c|c|c|c|c|}
\hline & \multicolumn{3}{|c|}{ Model 4: No care-giver } & \multicolumn{3}{|c|}{$\begin{array}{l}\text { Model 5: Child (in-law) } \\
\text { care-giver }\end{array}$} & \multicolumn{3}{|c|}{$\begin{array}{l}\text { Model 6: Grandchild } \\
\text { care-giver }\end{array}$} \\
\hline & OR & SE & PP & OR & SE & PP & OR & SE & PP \\
\hline Co-resident & Ref. & & 0.13 & Ref. & & 0.80 & Ref. & & 0.12 \\
\hline Networked & $3.60^{* *}$ & $1.5^{8}$ & 0.31 & $0.26 * * *$ & 0.10 & $0.5^{6}$ & 0.74 & $0.3^{8}$ & 0.09 \\
\hline Isolated & $7.05^{* *}$ & 4.39 & 0.43 & $0.02 * * *$ & 0.02 & 0.14 & $3.5^{8 *}$ & 2.26 & 0.31 \\
\hline Male & Ref. & & 0.25 & Ref. & & 0.63 & Ref. & & 0.11 \\
\hline Female & 0.60 & 0.29 & 0.19 & 1.60 & 0.68 & $0.7^{\circ}$ & 1.23 & $0.5^{6}$ & 0.13 \\
\hline Observations & 248 & & & 248 & & & 248 & & \\
\hline Pseudo $R^{2}$ & 0.215 & & & 0.275 & & & $0.05^{8}$ & & \\
\hline
\end{tabular}

Notes: OR: odds ratio. SE: robust standard error. PP: average predicted probability. Ref.: reference category. Control variables (same as in Table 2) not shown: full table available upon request.

Possible significance levels: $\dagger p<0.10, * p<0.05, * * p<0.01, * * * p<0.001$.

than their co-resident counterparts (Model 4). It is possible that some of these elders have indeed been 'abandoned' by their children, although they constitute a relatively small percentage of the sample. Moreover, as can be seen in Model 6, grandchildren often step in when neither a spouse nor a child is available to provide care. The role of gender also varies according to marital status. Notably, after controlling for gender differences in other covariates, married mothers have a higher risk of unmet care needs than married fathers $(p<0.001)$, but for single parents the effect is reversed $(p>0.10)$. 


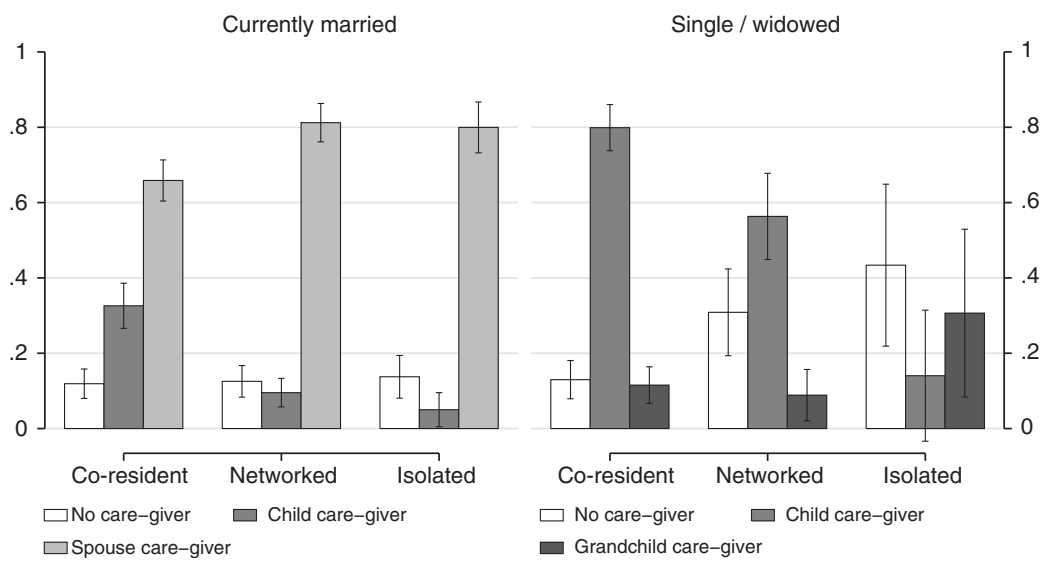

Figure 2. Predicted probabilities, by living arrangement and presence of spouse.

Notes: Average predicted probabilities from the regression models presented in Tables 3 and 4 . Spikes indicate 95 per cent confidence intervals. Based on responses to the question 'Who most often helps you with [list of ADLs and IADLs]?' The probabilities do not necessarily add up to 1 because respondents could indicate multiple care-givers or other care-givers.

\section{Family care-giving over the lifecourse}

Family care-giving arrangements tend to change over time in accordance with the needs of the recipient and the availability of various types of care-givers. As a result, comparatively older parents are expected to rely more heavily on their children and other relatives rather than on a spouse. To illustrate the effect of age, we can compare the predicted probabilities of having a particular care-giver at different ages. Figure 3 shows that spousal care-giving declines sharply with age, whilst the probability of having a child care-giver increases. The probability of not having a caregiver is highest around age 70 and then declines. Further research will be necessary to determine which lifecourse events induce a change in caregivers, and to distinguish between age and cohort effects.

\section{Discussion}

The purpose of this paper was to identify patterns in family care provision in rural China, which recently experienced an unprecedented decline in intergenerational co-residence. In particular, it tried to assess whether living close to children can be considered a functional equivalent to co-residence and how the presence of a spouse affects family care-giving choices.

CHARLS data indicate that approximately one out of every seven older parents in rural China did not receive any help with (I)ADLs, in spite of a 


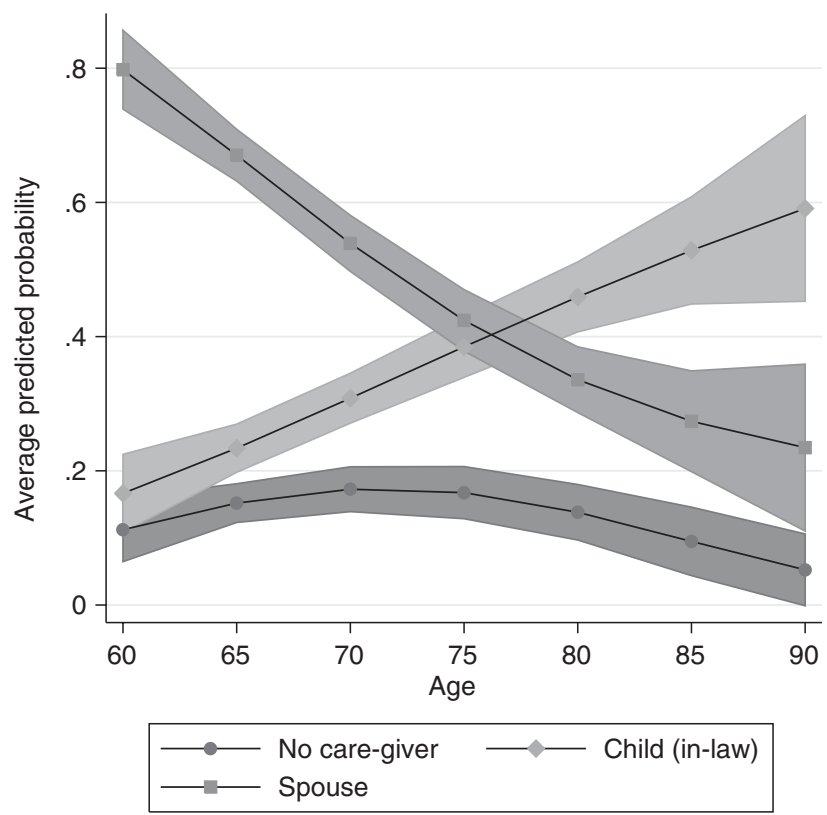

Figure 3. Main care-giver(s) of physically impaired elders, over age.

Notes: Average predicted probabilities from regression analyses on the full analytical sample (not shown). Shaded areas indicate 95 per cent confidence intervals. The respondents could indicate other or multiple care-givers.

reported need. This is higher than what was reported by Peng, Wu and Ling (2014), although their sample only included respondents aged 80 and above. The findings showed that older adults with unmet care needs are predominantly non-co-resident, which is in line with Hypothesis 1. It is important to note that this effect only occurred for widowed elders: those who lived with a spouse were equally (un) likely not to have a care-giver as the co-resident group. The presence of a spouse thus mediated the negative impact of not living with children, which is in line with Hypothesis 4 . The fact that widows - most of whom are female and have low living standards - are more likely to have unmet care needs is rather worrying. The Chinese government has tried to improve the position of elders by enshrining filial responsibility into law (Du 2013), but this is unlikely to resolve the complex problems that lead to deficiencies in inter-generational support.

The second hypothesis regarded parents that live close to their children rather than in the same household. The networked family arrangement is often seen as an alternative to co-residence, granting privacy and independence to both parents and children whilst maintaining the close inter-generational ties typical for the multi-generational household. The findings provided mixed evidence for this view. Married parents that lived 
independently were mostly cared for by their spouse, regardless of whether a child lived nearby. For single parents, however, having one or more children in the locality can provide important benefits.

The findings also showed that the spouse is the most common care-giver overall. Due to mortality and morbidity, however, comparatively older respondents are less likely to be able to rely on a spouse. Since care-giving by children increases with age (Hypothesis 5 ), there appears to be a hierarchy in family care-giving responsibilities, where children (or grandchildren) step in only when the spouse is no longer able to fulfil this role (see also Miller 2007; Xu 2001; Zimmer 2005). In this sense, Chinese caregiving patterns are rather similar to those observed in the West. This is a somewhat surprising finding because the discourse on care-giving in China and other Asian countries is largely focused on adult children. The predominance of spousal care-giving in rural China is likely a result of the unprecedented decline in co-residence rates. If, and under what circumstances, the independent living arrangement reflects the preferences of frail older people is a topic that deserves more attention in the Chinese context.

The findings of this study do not suggest that children have abandoned their aged parents. First of all, it was shown that care-giving is generally responsive to need. Parents that are widowed and/or comparatively older are more likely to receive care from a child. Secondly, the decision to leave care in the hands of spouses or even grandchildren reflects a likely adaptation to the changed economic circumstances in rural China. Young adults may be more important to their families by working in urban areas and remitting part of their salary to support family members back home. Indeed, there is ample evidence that most labour migrants provide significant financial support to their parents and maintain close emotional bonds (Biao 2007; Cai, Giles and Meng 2006; Du, Park and Wang 2005; Giles, Wang and Zhao 2011; Guo, Aranda and Silverstein 2009; Liu 2014).

The above findings should be seen in the light of a number of limitations. First of all, since the paper is based on cross-sectional data, it is not able to account for lifecourse transitions in both care-giving and living arrangement. There is substantial evidence that parents move in with their children (or vice versa) in order to receive care (Korinek, Zimmer and Gu 2011; Miller 2007; $\mathrm{Xu}$ 2001; Zimmer and Korinek 2010). When further waves of CHARLS become available, it will be possible to relate changes in the location of parents and children to care-giving arrangements. For example, it might be the case that networked children are more likely than migrant children to move in with parents and become primary care-givers. Furthermore, I could not control for certain (potential) confounding variables such as emotional closeness between parents and children because they were not measured in CHARLS. Previous studies have shown that intra-family 
conflicts and disagreements are an important reason for disruptions in the inter-generational support system. Finally, the paper focused on primary care-givers only. Future research may want to consider secondary caregivers as well as task specificity in care-giving.

These limitations notwithstanding, the study provides a detailed account of informal family care provision in rural China, using a comprehensive and recent data-set of functionally impaired elders. It extends previous literature by comparing different types of care-givers and living arrangements, particularly the role of spouses and networked children.

The findings raise serious questions about the sustainability of the 'traditional' way of providing elder care in rural China, in which the family takes up the entire care-giving burden. CHARLS data show that a majority of physically impaired older adults now live independently from their children and are primarily cared for by their spouse. This development is likely to continue as increasing longevity, low birth rates and large-scale rural-to-urban migration further erode the ratio of potential child caregivers to recipients of care. It is important to note that population ageing is still at an early stage in China; the cohorts that were most affected by the fertility reduction policy are only beginning to approach later life.

Still, even today a substantial number of older adults do not receive the care that they need, and they tend to belong to the most disadvantaged segments of the older population. The plight of rural elders has received considerable attention in the Chinese public discourse, and there is a growing awareness that families cannot be expected to shoulder the entire caregiving burden alone. Through the New Cooperative Medical Insurance Scheme (established in 2008) and the New Rural Pension Programme (established in 2009), China has recently expanded basic health insurance and (minimal) pension coverage to the majority of the rural population, which is a major achievement. With respect to long-term care, however, the government's effort has been less comprehensive. Experts have argued for the establishment of a long-term care insurance scheme similar to the ones found in Japan and Korea, as well as for the expansion of (community-based) nursing homes and home care services (Du 2013; Glass, Gao and Luo 2013; Peng, Wu and Ling 2014). Given the persistently low income levels of rural elders, such initiatives would need significant public funding in order to reach the most vulnerable groups.

\section{Acknowledgements}

The study uses data from CHARLS Wave 1 (Baseline), updated on 13 March 2013. CHARLS has received critical support from Peking University, the National Natural 
Science Foundation of China, the Behavioral and Social Research Division of the National Institute on Aging and the World Bank. For more information, see http://charls.ccer.edu.cn/en. It also makes use of the harmonised CHARLS dataset and Codebook, Version B as of June 2015 developed by the Gateway to Global Aging Data. The development of the harmonised CHARLS was funded by the National Institute on Ageing (Ro1 AGo3o153, RC2 AGo36619, 1 Ro3AGo43052). For more information, see www.g2aging.org.

\section{NOTES}

1 It is estimated that more than 80 per cent of rural migrants are younger than 40 (Cai et al. 2012: 14).

2 The urban-rural classification is provided by the National Bureau of Statistics of China, who define a locality as urban 'if it is located in a city, suburb of a city, a town, suburb of a town, or other special areas where nonfarm employment constitutes at least 70\% of the work force' (Zhao et al. 2013: 19).

3 Population ageing is particularly pronounced in rural China: the old-age dependency ratio is set to increase from 13.3 per cent in 2008 to 34.4 per cent in 2030 (Cai et al. 2012: 23).

4 Currently, only o.8 per cent of the older population stays in residential care facilities, most of which are located in urban areas (Chow 2011).

5 I also tested for self-rated health and cognitive capability, but this did not significantly improve the model.

6 Self-reported living standard is considered the most reliable economic indicator because it is collected individually (as opposed to household income) and because of inherent problems collecting 'hard' income data in a setting characterised by informal labour and subsistence agriculture.

7 The sample includes parents over 60 only, most of whom had children before the introduction of the fertility reduction policy in 1979 .

\section{References}

Arber, S. 2013. Gender, marital status and intergenerational relations in a changing world. In McDaniel, S. A. and Zimmer, Z. (eds), Global Ageing in the Twenty-first Century. Ashgate, Farnham, UK, $215^{-34}$.

Barrientos, A., Gorman, M. and Heslop, A. 2003. Old age poverty in developing countries: contributions and dependence in later life. World Development, 31, 3, $555^{-70 .}$

Benjamin, D., Brandt, L. and Rozelle, S. 200o. Aging, wellbeing, and social security in rural northern China. Population and Development Review, 26, supplement, $89-116$.

Biao, X. 2007. How far are the left-behind left behind? A preliminary study in rural China. Population, Space and Place, 13, 3, 179-91.

Biddlecom, A., Chayovan, N. and Ofstedal, M. B. 2002. Intergenerational support and transfers. In Hermalin, A. I. (ed.), The Well-being of the Elderly in Asia: A Fourcountry Comparative Study. University of Michigan Press, Ann Arbor, Michigan, $185^{-229}$. 
Cai, F., Giles, J. and Meng, X. 2006. How well do children insure parents against low retirement income? An analysis using survey data from urban China. Journal of Public Economics, 9o, 12, 2229-55.

Cai, F., Giles, J., O'Keefe, P. and Wang, D. 2012. The Elderly and Old Age Support in Rural China: Challenges and Prospects. World Bank, Washington DC.

Cantor, M. H. 1979. Neighbors and friends: an overlooked resource in the informal support system. Research on Aging, 1, 4, 434-63.

Chappell, N. L. 1991. Living arrangements and sources of caregiving. Journal of Gerontology, 46, 1, 1-8.

Chow, J. C. 2011 . Exploring the community-based service delivery model: elderly care in China. International Social Work, 54, 3, 374-87.

Cong, Z. and Silverstein, M. 2011 . Intergenerational exchange between parents and migrant and nonmigrant sons in rural China. Journal of Marriage and Family, 73, 1, 93-104.

Croll, E. J. 20o6. The intergenerational contract in the changing Asian family. Oxford Development Studies, 34, 4, 473-91.

$\mathrm{Du}, \mathrm{P} .2013$. Intergenerational solidarity and old-age support for the social inclusion of elders in Mainland China: the changing roles of family and government. Ageing E Society, 33, 1, 44-63.

Du, Y., Park, A. and Wang, S. 2005. Migration and rural poverty in China. Journal of Comparative Economics, 33, 4, 688-709.

Giles, J. and $\mathrm{Mu}, \mathrm{R} .2007$. Elderly parent health and the migration decision of adult children: evidence from rural China. Demography, 44, 2, 265-88.

Giles, J., Wang, D. and Zhao, C. 2011. Can China's rural elderly count on support from adult children? Implications of rural-to-urban migration. Journal of Population Ageing, 3, 3/4, $183-204$.

Glass, A. P., Gao, Y. and Luo, J. 201 3. China: facing a long-term care challenge on an unprecedented scale. Global Public Health: An International Journal for Research, Policy and Practice, 8, 6, 725-38.

Guo, M., Aranda, M. P. and Silverstein, M. 2009. The impact of out-migration on the inter-generational support and psychological wellbeing of older adults in rural China. Ageing and Society, 29, 7, $1085^{-1104}$.

Guo, M., Chi, I. and Silverstein, M. 2009. Intergenerational support of Chinese rural elders with migrant children: do sons' or daughters' migrations make a difference? Journal of Gerontological Social Work, 52, 5, 534-54.

Haberkern, K., Schmid, T. and Szydlik, M. 2015 . Gender differences in intergenerational care in European welfare states. Ageing $\mathcal{E}$ Society, 35, 2, 298-320.

Hermalin, A.I. (ed.) 2002. The Well-being of the Elderly in Asia: A Four-country Comparative Study. University of Michigan Press, Ann Arbor, Michigan.

Hoi, L. V., Thang, P. and Lindholm, L. 2011 . Elderly care in daily living in rural Vietnam: need and its socioeconomic determinants. BMC Geriatrics, 11, 81 .

Holroyd, E. A. and Mackenzie, A. E. 1995. A review of the historical and social processes contributing to care and caregiving in Chinese families. Journal of Advanced Nursing, 22, 3, 473-9.

Ikels, C. 2008. Economic reform and intergenerational relationships in China. In Goodman, R. and Harper, S. (eds), Ageing in Asia. Volume 4, Routledge, London, 14-27.

Knodel, J. and Chayovan, N. 2012. Inter-generational family care for and by older people in Thailand. International Journal of Sociology and Social Policy, 32, 11, 682-94. 
Knodel, J. and Ofstedal, M. B. 2002. Patterns and determinants of living arrangements. In Hermalin, A. I. (ed.), The Well-being of the Elderly in Asia: A Four-country Comparative Study. University of Michigan Press, Ann Arbor, Michigan, 143-84.

Korinek, K., Zimmer, Z. and Gu, D. 2011 . Transitions in marital status and functional health and patterns of intergenerational coresidence among China's elderly population. Journals of Gerontology: Social Sciences, 66B, 2, 26o-70.

Lei, X., Strauss, J., Tian, M. and Zhao, Y. 2011 . Living Arrangements of the Elderly in China: Evidence from CHARLS. RAND Labor and Population Working Paper Series, WR-866. Available online at http://www.rand.org/content/dam/rand/ pubs/working_papers/2011/RAND_WR866.pdf [Accessed 12 November 2014].

Litwak, E. and Kulis, S. 1987. Technology, proximity, and measures of kin support. Journal of Marriage and Family, 49, 3, 649-61.

Liu, J. 2014. Ageing, migration and familial support in rural China. Geoforum, 51, $305^{-12 .}$

Miller, E. T. 2007. 'Living independently is good': residence patterns in rural north China reconsidered. Care Management Journals, 8, 1, 26-32.

National Bureau of Statistics of China 2013. China Statistical Yearbook 2013. China Statistics Press, Beijing.

Peng, R., Wu, B. and Ling, L. 2014. Undermet needs for assistance in personal activities of daily living among community-dwelling oldest old in China from 2005 to 2008. Research on Aging, 37, 2, 148-70.

Penning, M.J. 1990. Receipt of assistance by elderly people: hierarchical selection and task specificity. The Gerontologist, 30, 2, 220-7.

Silverstein, M., Cong, Z. and Li, S. 2006. Intergenerational transfers and living arrangements of older people in rural China: consequences for psychological well-being. Journals of Gerontology: Social Sciences, 61 B, 5, 256-66.

Silverstein, M. and Litwak, E. 1993. A task-specific typology of intergenerational family structure in later life. The Gerontologist, 33, 2, $25^{8-64}$.

Song, L., Li, S. and Feldman, M. W. 2012 . Out-migration of young adults and gender division of intergenerational support in rural China. Research on Aging, 34, 4, 399-424.

Thang, L. L. 2010. Intergenerational relations: Asian perspectives. In Dannefer, D. and Phillipson, C. (eds), The Sage Handbook of Social Gerontology. Sage, London, 202-15.

Thøgersen, S. and Anru, N. 2008. 'He is he, and I am I': individual and collective among China's rural elderly. European Journal of East Asian Studies, 7, 1, 1 1-37.

Uhlenberg, P. 1996. The burden of aging: a theoretical framework for understanding the shifting balance of caregiving and care receiving as cohorts age. The Gerontologist, 36, 6, 761-7.

Vlachantoni, A., Shaw, R. J., Evandrou, M. and Falkingham, J. 2013. The determinants of receiving social care in later life in England. Ageing E् Society, 35, 2, $321-45$.

Whyte, M. K. 2003. Introduction. In Whyte, M. K. (ed.), China's Revolutions and Intergenerational Relations. Center for Chinese Studies, University of Michigan, Ann Arbor, Michigan, 3-30.

Whyte, M. K. 2004. Filial obligations in Chinese families: paradoxes of modernization. In Ikels, C. (ed.), Filial Piety: Practice and Discourse in Contemporary East Asia. Stanford University Press, Stanford, California, 106-27.

Wolff, J. L. and Kasper, J. D. 20o6. Caregivers of frail elders: updating a national profile. The Gerontologist, 46, 3, 344-56.

$\mathrm{Xu}$, Y. 2001. Family support for old people in rural China. Social Policy E Administration, 35, 3, 307-20. 
Yang, Y. 2010. No way out but working? Income dynamics of young retirees in Korea. Ageing E Society, 31, 2, $265^{-87}$.

Yarger, J. and Brauner-Otto, S. R. 2014. Non-family experience and receipt of personal care in Nepal. Ageing E Society, 34, 1, 106-28.

Zhan, H.J. and Montgomery, R. J. V. 2003. Gender and elder care in China: the influence of filial piety and structural constraints. Gender $\mathcal{E}$ Society, 17, 2, 209-29.

Zhang, H. 2004. 'Living alone' and the rural elderly: strategy and agency in post Mao rural China. In Ikels, C. (ed.), Filial Piety: Practice and Discourse in Contemporary East Asia. Stanford University Press, Stanford, California, 63-87.

Zhang, Y. and Yeung, W. J.J. 201 2. Shifting boundaries of care in Asia: an introduction. International Journal of Sociology and Social Policy, 32, 1 1, 612-22.

Zhang, Z., Gu, D. and Luo, Y. 2014. Coresidence with elderly parents in contemporary China: the role of filial piety, reciprocity, socioeconomic resources, and parental needs. Journal of Cross-cultural Gerontology, 29, 3, 259-76.

Zhao, Y., Strauss, J., Giles, J., Hu, P. P., Liu, M. and Smith, J. P. 201 3. China Health and Retirement Longitudinal Study: 201 I-2OI 2 National Baseline Users' Guide. Available online at http://charls.ccer.edu.cn/uploads/document/201 1-charls-wave 1/application/CHARLS_nationalbaseline_users_guide.pdf [Accessed 5 January $2015]$.

Zimmer, Z. 2005. Health and living arrangement transitions among China's oldest old. Research on Aging, 27, 5, 526-55.

Zimmer, Z. and Korinek, K. 2010 . Shifting coresidence near the end of life: comparing decedents and survivors of a follow-up study in China. Demography, 47, 3, $537-54$.

Zimmer, Z. and Kwong, J. 2003. Family size and support of older adults in urban and rural China: current effects and future implications. Demography, 4o, 1, 23-44.

Accepted 6 November 2OI5; first published online 22 December 2015

Address for correspondence:

Rob J. Gruijters,

Berlin Graduate School of Social Sciences (BGSS),

Humboldt Universität zu Berlin,

Luisenstraße $5^{6 \text {, }}$

10117 Berlin, Germany

E-mail: rob.gruijters@hu-berlin.de 